\title{
Rancang Bangun Game Tradisional "Tambah Satu” berbasis Platform Android
}

\author{
Andro Geotan Immanuel Hutabarat ${ }^{1}$, Ayung Candra Padmasari ${ }^{2}$ \\ 1,2 Pendidikan Multimedia, Universitas Pendidikan Indonesia \\ Jl. Raya Cibiru Km 15 Bandung 40393 \\ Email: androgeotan378@upi.edu
}

\begin{abstract}
ABSTRAK
Permainan tradisional merupakan salah satu ragam dari berbagai budaya yang ada di Indonesia. Budaya adalah suatu cara hidup yang berkembang, dan dimiliki bersama oleh sebuah kelompok orang, dan diwariskan dari generasi ke generasi. Budaya terbentuk dari banyak unsur yang rumit, termasuk sistem agama,adat istiadat, bahasa, perkakas, pakaian, bangunan, karya seni, dan permainan. Beragam budaya di Indonesia banyak yang mulai terkikis, akibat perkembangan jaman yang menuju modernisasi, salah satunya permainan tradisional. "Tambah Satu" merupakan salah satu permainan tradisional yang sangat digemari banyak kalangan pada masanya, namun mulai kehilangan eksistensinya, dikarenakan tidak dapat beradaptasi dengan perkembangan jaman. Salah satu sistem operasi yang eksis dalam menunjuang kebutuhan permainan saat ini adalah android. Rancangan bangun game ini menggunakan platform android berbasis Linux dengan memanfaatkan perangkat bergerak layar sentuh seperti telepon pintar. Sistem operasi android bersifat open-source dan membebaskan penggunanya untuk menciptakan aplikasi sendiri secara bebas dan mandiri. Metode perancangan game ini memanfaatkan pendekatan transformasi game dengan metode ATUMICS, dan perancangan game dengan metode MDLC. Tujuan dari pendekatan metode tersebut agar tercipta permainan tradisional berbasis digital tanpa mengurangi unsur kebudayaan dari game tersebut. Pengujian user interface game "Tambah Satu", menggunakan metode kuesioner melibatkan 30 responden, dengan pengolahan data menggunakan skala Guttman untuk pengujian user interface, dan skala Likert untuk pengujian user experience. Hasil dari pengujian user interface game "Tambah Satu" memperoleh nilai sebesar 0,65 dengan kelompok kategori sebagai netral digunakan, dan penilaian user experience didapatkan sebesar 6,45, diketegorikan mudah digunakan oleh pengguna.
\end{abstract}

Kata Kunci: Budaya, Indonesia, Android, Tambah Satu, Game, Permainan Tradisional

\section{ABSTRACT}

Traditional games are one of the various cultures in Indonesia. Culture is a way of life that develops, is shared by a group of people, and is passed down from generation to generation. Culture is made up of many complex elements, including religious systems, customs, language, tools, clothing, buildings, art, and games. Many diverse cultures in Indonesia are beginning to erode, due to the development of the era leading to modernization, which one is traditional games. "Tambah Satu" is one of the traditional games that is very popular with many people in his time, but began to lose its existence, because it can't adapt to the changing of the times. One operating system that exists in supporting the needs of the game at this time is android. The design of this game build uses a Linux-based android platform by utilizing touch screen mobile devices such as smartphones. Android operating system is open-source and free users to create their own applications freely and independently. This game design method utilizes the game transformation approach with the ATUMICS method, and game design using the MDLCmethod. The aim of the method approach is to create a digital-based traditional game without reducing the cultural elements of the game. Testing the user interface of "Tambah Satu"game, using a questionnaire method involving 30 respondents, with data processing using the Guttman scale for testing the user interface, and Likert scale for testing the user experience. The results of testing the user interface game "Tambah Satu" obtained a value of 0.65 with the group category as neutral to use, and the user experience assessment obtained at 6.45, categorized as easy to use by users.

Keywords: Culture, Indonesia, Android, Tambah Satu, Games, Traditional Game 


\section{Pendahuluan}

Permainan tradisional sangatlah populer sebelum teknologi masuk ke Indonesia. Dahulu, anak-anak bahkan kalangan dewasa pun bermain dengan alat seadanya yang mengandalkan fisik dan otak. Namun kini, mereka sudah bermain dengan permainan-permainan berbasis teknologi yang berasal dari luar dan mulai meninggalkan permainan tradisional (Hikmah, 2017). Berbagai macam upaya dilakukan mulai dari mengenalkan permainan tradisional agar kembali berkembang, sebagai contoh melalui pembelajaran museum, internet, dan berbagai hal lain. Namun hasilnya nihil, dan selalu tertutupi akibat perubahan zaman yang begitu cepat. Seiring perubahan zaman, permainan tradisional perlahan-lahan mulai terlupakan oleh banyak kalangan, bahkan tidak sedikit dari mereka yang belum mengenal permainan tradisional. Secara perkembangan teknologi, kemajuan teknologi harus di tanggapi positif, dan memanfaatkan perkembangannya untuk mengembangkan budaya yang mulai luntur. Perkembangan zaman sudah menunjukan, bahwa setiap individu mempunyai kecenderungan berkembang dalam hal cara belajar di Indonesia di masa mendatang yaitu, berkembangnya pendidikan bersifat terbuka jarak jauh, sharing resourch, dan penggunaan teknologi interaktif dan multimedia (Munir dalam Sari, 2019). Salah satu contoh pembelajaran budaya, berupa game tradisional. Game adalah salah satu jenis aktifitas yang dilakukan dan terlihat nyata namun dalam konteks sebuah permainan (Suyasa, 2017). Dalam paper kali ini, peneliti mengambil sebuah acuan dari penelitian yang dilakukan oleh (Permana, 2019) dari Universitas Pendidikan Indonesia, dan telah terbit pada jurnal Edsence Vol 1, No. 1, Tahun 2019, dengan Rancang Bangun Aplikasi Pendeteksi Jenis Golongan Darah Berdasarkan Konsep Kepercayaan Rakyat Jepang (Minkan Shinko). Dari penelitian ini, peneliti menyimpulkan bahwa sebuah kepercayaan yang berupa budaya masyarakat Jepang, dapat diaplikasikan dan dikaitkan dengan ilmu pengetahuan berbasis teknologi. Sama halnya dengan konsep game "Tambah Satu" yang dirancang dalam penelitian ini, yang bertujuan sebagai media pembelajaran berbasis kebudayaan.

Perkembangan ilmu teknologi di dunia maya hingga saat ini menunjukkan perkembangan ide dan karya baru diberbagai bidang, salah satunya adalah teknologi game yang pada masa kini menjadi sorotan (Padmasari, 2019). Dijaman sekarang, sebuah game yang ada dalam perangkat bergerak (mobile) tentu dapat memberikan hiburan yang menarik kepada para pecinta game, dikarenakan game dapat dimainkan dimana saja secara praktis dan mudah. Game yang sederhana namun tidak membosankan serta dapat membuat pemain ingin kembali untuk memainkannya adalah konsep game yang tepat diterapkan dalam game edukasi (Krisnawan, 2016). Game edukasi merupakan sebuah aplikasi permainan, yang melalui permainan tersebut dapat memberikan materi ataupun informasi yang bersifat mendidik kepada pengguna (Alam, 2017). Pengedukasian disini berupa hal pengembangan budaya dari game yang sudah jarang dikenal dijaman sekarang, bertujuan agar dikenal oleh kalangan masyarakat, dan dapat mengedukasi masyarakat lainnya secara luas. Permasalahan yang akan dihadapi dalam penelitian ini adalah tentang bagaimana cara me-redesain sebuah game tradisional yang mewajibkan kontak fisik antara kedua pemain, menjadi game digital, tanpa mengurangi nilai budaya dan nilai tradisional dalam game tersebut. Diharapkan masyarakat lebih mengenal permainan jaman dahulu, bahkan merasa nostalgia jika pernah memainkannya.

Game yang akan dirancang dalam penelitian ilmiah ini bernama "Tambah Satu", merupakan salah satu permainan tradisional yang banyak digemari banyak kalangan, dan sangat populer di Indonesia pada masanya. Dalam game ini mengangkat konsep sebuah game edukasi tradisional yang diaplikasikan dalam sebuah platform android. Android merupakan sistem operasi yang terbuka bagi para pengembang untuk menciptakan aplikasi mereka sendiri secara bebas. (Sanjaya, 2016). Dalam tahap transformasi permainan tradisional menjadi game digital di platform android, dilakukan tanpa mengurangi nilai-nilai yang terkandung dalam permainan tradisional. Menurut KBBI, mengartikan transformasi sebagai perubahan rupa (bentuk, sifat, fungsi, dan sebagainya). Dengan menggunakan kombinasi metode ATUMICS (Artefact, Technique, Utility, Material, Icon, Concept, dan Shape) dan Multimedia Development Life Cycle (MDLC) dalam pengembangan game "Tambah Satu", tidak akan mengurangi nilai tradisional dalam game "Tambah Satu" (Hidayat, 2019). Dan pengujian game "Tambah Satu" dilakukan dengan metode kuisioner yang disebar kepada pengguna game tersebut. Diharapkan dalam pengembangan game ini dapat ikut serta melestarikan game tradisional, meningkatkan kecintaan masyarakat luas dengan game tradisional berbasis digital, dan mengedukasi masyarakat luas terhadap pentingnya melestarikan budaya. 


\section{Metode Penelitian}

\subsection{Model Pengembangan Game "Tambah Satu"}

Dalam pengembangan model game "Tambah Satu", akan diterapkan sesuai konsep berikut:

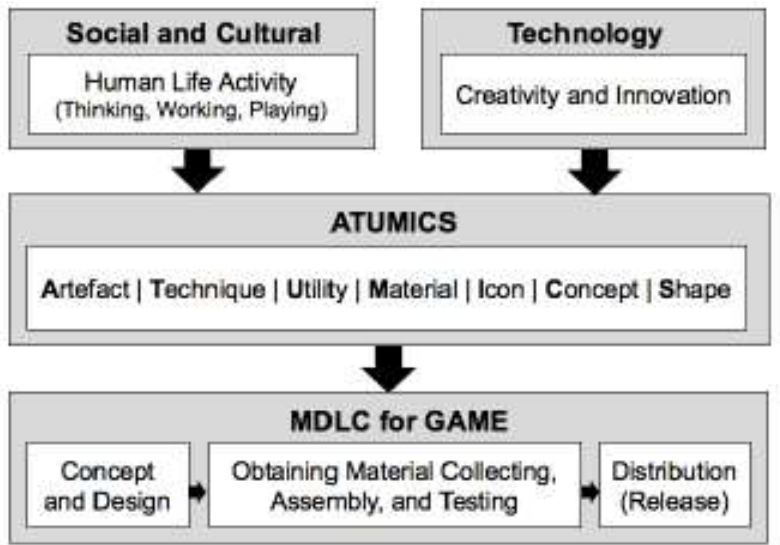

Gambar 1. Konsep model pengembangan game "Tambah Satu"

Konsep tersebut menjelaskan konsep hal yang dilakukan sehari-hari seperti berpikir, bekerja dan bermain, yang dipengaruhi oleh sosial budaya (Hidayat : 2019). Permainan "Tambah Satu" hadir karena, dipengaruhi oleh kondisi sosial budaya di tempat permainan itu dimainkan. Dikombinasikan dengan kreatifitas dan inovasi yang dipengaruhi oleh teknologi. Merangsang manusia untuk membuat sesuatu hal yang kreatif dan inovatif dilandasi oleh teknologi. Pada tahap ini terjadi pergeseran pada aspek bermain dengan berbagai kondisi sosial budaya yang ada, ditambah dengan kondisi lingkungan yang tidak selalu mendukung, adanya kemampuan dalam hal berkreasi dan membuat inovasi dalam bantuan teknologi, dapat mengubah permainan tradisional "Tambah Satu", menjadi permainan modern berbasis digital android. Penyebab hadirnya konsepsi ini dikarenakan adanya keinginan untuk melestarikan game tradisional yang mulai luntur dalam kehidupan bermasyarakat, dan adanya kerinduan dalam memainkan permainan "Tambah Satu", bagi generasi 90-an untuk menghadirkan memori nostalgia saat memainkan permainan "Tambah Satu".

Analisis perancangan game melalui pendekatan ATUMICS, dilanjutkan dengan pembangunan model game melalui pendekatan MDLC, merupakan suatu kombinasi yang baik untuk mengubah game tradisional menjadi game modern, tanpa mengurangi esensi budaya nya, menciptakan game tersebut agar layak dipakai, dan tujuan dari game "Tambah Satu" tercapai.

\subsection{Transisi permainan "Tambah Satu" ke bentuk digital}

Adaptasi permainan "Tambah Satu" dari permainan tradisional kedalam permainan digital dengan menggunakan metode ATUMICS yang bertujuan untuk mengklasifikasikan elemen budaya tanpa mengurangi esensi budaya dari game "Tambah Satu". Penjelasan tahap transisi akan dijelaskan dalam level mikro dan level makro, sebagai berikut:

\subsubsection{Artefact/Artefak}

Artefact dari permainan "Tambah Satu" dapat dikategorikan sebagai berikut :

a. Maksud : Permainan Tambah Satu dimainkan untuk semua kalangan dari anak-anak hingga dewasa.

b. Tujuan : Tujuan dari permainan ini untuk mengasah kemampuan otak dalam berhitung, dan memadupadankan bilangan. 


\subsubsection{Technique/Teknik}

Teknik bermain dalam permainan Tambah Satu adalah sebagai berikut :

a. Teknik Permainan : Teknik permainan meliputi hal seputar prosedur permainan, cara bermain, dan standar penentuan yang menang dan yang kalah.

Permainan ini membutuhkan dua orang pemain, kondisi pemain harus berhadap-hadapan. Lalu mereka menentukan siapa yang akan melangkah pertama, dan melakukan suit (gunting, batu, kertas). Setelah menemukan pemain yang pertama melangkah, setiap pemain menyiapkan jari telunjuk kedua tangan, menunjuk kearah depan lawannya, posisi jari tangan dibawah dada.

Pemain yang melangkah lebih awal berkesempatan untuk menyentuh jari tangan lawan, dan jari tangan lawan akan bertambah sesuai dengan kondisi jari tangan yang lawan punya. Sebagai contoh jika kita mempunyai jumlah dalam tangan kiri kita 2, dan kita menyentuh jari tangan lawan, yang mempunya jumlah 1 , maka setelah kita menyentuhnya, total yag dimiliki jari tangan lawan $(2+1=3)$, jumlah total jari tangan dari lawan sebanyak 3 jari tangan. Nilai yang dimiliki setiap jari tangan kanan dan kiri adalah sebanyak 4, jika hasil pertambahannya menghasilkan jumlah 5 jari tangan, makan jari di tangan akan kuncup, atau 0, jika pertambahan melebihi 5, maka jumlah pertambahan akan dikurangi 5, sebagai contoh, jika jari tangan lawan 4 dan kita menyentuh jari lawan dengan akan 3 akan menghasilkan jumlah $(4+3=7>5$, jika lebih besar maka 7-5 sisa 2), maka dijari tangan lawan akan mempunyai 2 jumlah jari tangan.

Selain itu ada kondisi dimana pemain bisa memadupadankan jumlah yang dimiliki pemain. Sebagai contoh, jika jari tangan kiri berjumlah 4, dan jari tangan kanan berjumlah 1, maka kita dapat memadupadankan, dengan mengadukan tangan kiri, dan tangan kanan, sejumlah 3 ditangan kiri, dan 2 ditangan kanan, atau 1 tangan kiri, dan 4 tangan kanan, seperti itu seterusnya, dengan catatan jumlah kedua tangan sama dan tidak berubah.

Dan peraturan saat bermain jika seseorang yang melakukan swap/memadupadankan, akan menghabiskan 1 giliran dan berganti kepada lawannya untuk menggunakan giliran tersebut. Seperti itu seterusnya, dan kondisi akan dikatakan menang jika yang lebih cepat habis jumlah, di kedua tangannya, dan menghasilkan jumlah total jari 0 dari tangan kanan dan kiri, maka itulah pemenangnya.

b. Keahlian : Persiapan yang dibutuhkan pemain dalam melakukan game ini adalah mempunyai keahlian cepat dalam menghitung, ketelitian dalam mengambil tindakan, dan strategi dalam bermain, agar mencapai total 0 pada jumlah jari tangan kanan dan kiri, agar memenangkan permainan tersebut.

\subsubsection{Utility/Utilitas}

Utility yang dibutuhkan dalam permainan "Tambah Satu", sebagai berikut:

a. Fungsi : Permainan "Tambah Satu" dimainkan untuk mengisi waktu luang,dan turnamen secara terbuka yang digelar diacara kebudayaan.

b. Kegunaan : Permainan "Tambah Satu" dapat dijadikan sebagai sarana hiburan dalam mengisi waktu luang dan sosialisasi antar individu.

c. Kebutuhan : Permainan "Tambah Satu" dapat dilakukan diberbagai kondisi, kondisi didalam ruangan, atau diluar. Dan tidak dibatasi oleh tenggat umur, dikarenakan dapat dimainkan disegala usia tanpa terkecuali.

\subsubsection{Material/Bahan}

Material yang dibutuhkan dalam permainan "Tambah Satu", sangat mudah untuk didapatkan, dan dapat menggunakan material lain. Buku tulis/kertas untuk menghitung jumlah skor yang didapatkan pemain dan membuat klasifikasi turnamen jika mengadakan turnamen "Tambah Satu". 


\subsubsection{Icon/Ikon}

Permainan "Tambah Satu", diidentifikasi melalui permainan adu ketangkasan, dan kemampuan berpikir dalam hal pertambahan, maupun memadupadankan jumlah bilangan, untuk mempertoleh kemenangan.

\subsubsection{Concept/Konsep}

Konsep dalam permainan "Tambah Satu", dapat dilihat dari hasil visualisasi, bentuk, dan ikon, dan kegunaan permainan saat dimainkan . Permainan ini dapat dilakukan diluar atau didalam ruangan, dengan peralatan permainan yang sangatlah mudah diperoleh.

\subsubsection{Shape/Bentuk}

Unsur shape dalam permainan "Tambah Satu", dikatakan tidak ada dikarenakan wujud dari permainan "Tambah Satu", yang simpel tanpa banyak hal yang harus dipersiapkan.

\subsubsection{Motivasi}

Hal motivasi yang dimaksud menjelaskan level makro dari permainan "Tambah Satu", adalah sebagai berikut:

a. Motivasi utama : Motivasi dalam hal yang berkaitan dengan budaya, yang bertujuan untuk melestarikan budaya, dalam hal permainan. Motivasi ini ditujukan agar masyarakat luas, dari berbagai kalangan dapat merasakan pengalaman dan kegembiraan saat memainkan permainan "Tambah Satu".

b. Motivasi sekunder : Motivasi dalam hal sosial budaya, dan ekonomi. Motivasi sosial budaya dalam permainan "Tambah Satu", adalah sebagai sarana komunikasi dan kerjasama yang baik antar permain, dalam permainan tradisional maupun dalam bentuk digital. Motivasi ekonomi yang ditimbulkan adalah dapat menjadikan game "Tambah Satu" dalam bentuk komoditi digital, dan dapat dijual secara meluas dimasyarakat nasional maupun internasional.

Dari hasil pendekatan bermodel ATUMICS diatas, maka dapat menghasilkan transisi dari permainan tradisional ke permainan digital, dengan berbagai perbandingan dengan kondisi permainan sesungguhnya, dan mengalami benyak penyesuaian dalam bentuk digital. Dan akan dijelaskan dalam tabel dibawah ini :

Tabel 1. Hasil transisi permainan tradisional ke digital

\begin{tabular}{|l|l|l|}
\hline \multicolumn{1}{|c|}{ Tambah Satu } & \multicolumn{1}{|c|}{ Game Digital } & \multicolumn{1}{|c|}{ Penyesuaian Peraturan } \\
\hline $\begin{array}{l}\text { Saat memadupadankan, dalam } \\
\text { permainan tradisional dengan cara } \\
\text { mengadu tangan kiri dan kanan, lalu } \\
\text { melakukan perpaduan / swap / } \\
\text { refresh jumlah total }\end{array}$ & Tidak dapat mengadu tangan & $\begin{array}{l}\text { Memberi tombol khusus untuk } \\
\text { swap / refresh pada game digital, } \\
\text { lalu pemain menentukan berapa } \\
\text { jumlah yang ada ditangan kanan, } \\
\text { dan berapa jumlah yang ada } \\
\text { ditangan kiri }\end{array}$ \\
\hline $\begin{array}{l}\text { Pemain yang mendapat giliran tidak } \\
\text { diberi tenggat waktu }\end{array}$ & $\begin{array}{l}\text { Lamanya giliran akan diberi } \\
\text { tenggat waktu sebesar 8 detik }\end{array}$ & $\begin{array}{l}\text { Dalam game digital akan diberi } \\
\text { waktu mundur sebesar 8 detik } \\
\text { untuk memacu pemain agar } \\
\text { berpikir lebih cepat, dan } \\
\text { permainan tidak memakan wakt } \\
\text { yang cukup lama. }\end{array}$ \\
\hline
\end{tabular}

Berikut alur antarmuka yang akan didapatkan dalam game"Tambah Satu": 


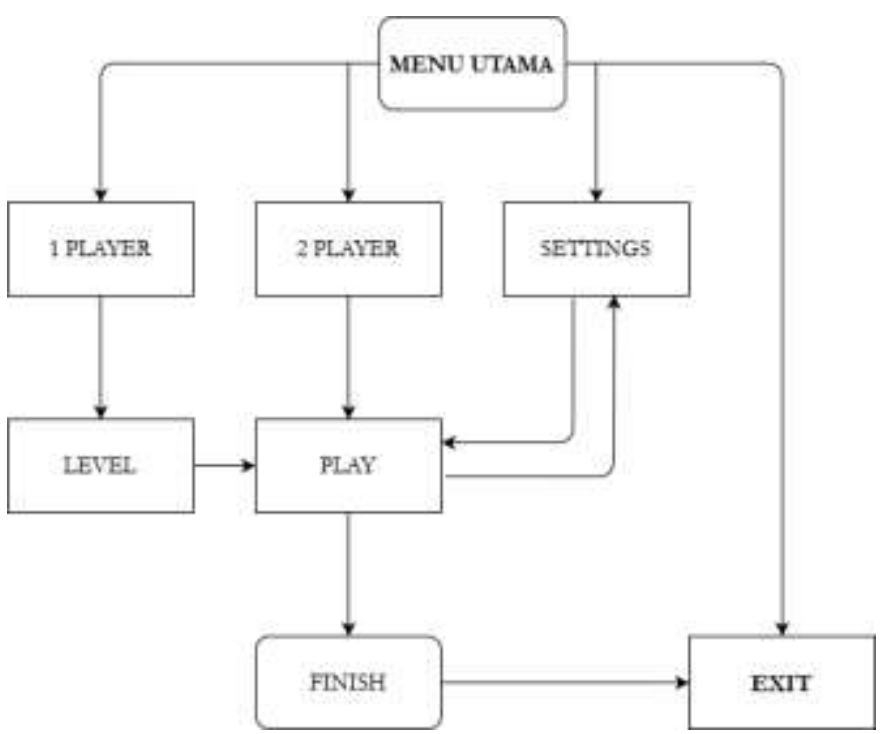

Gambar 2. Skema alur Tampilan interface user

Dan setelah menampilkan alur tampilan dalam game, selanjutnya beralih alur decission tree yang akan dihadapi player saat masuk kedalam permainan

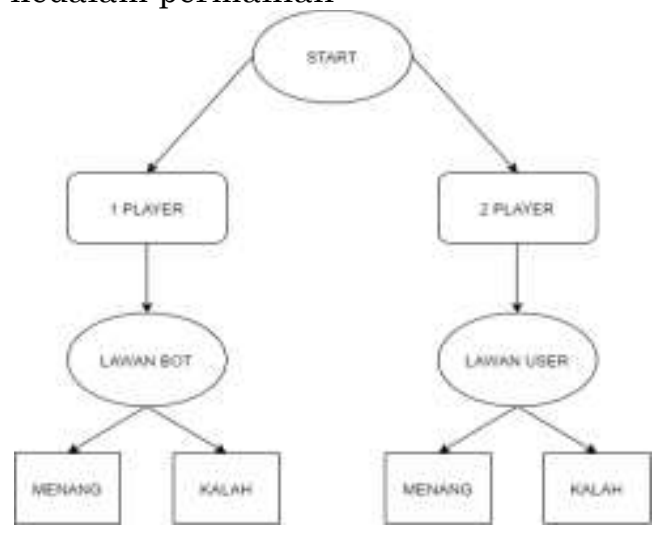

Gambar 3. Decission Tree dalam game

Dan berikut finite state machine yang akan dihadapi player jika player memilih menu 1 player, dimana player akan melawan bot. Dan berikut finite state machine bot di game "Tambah Satu".

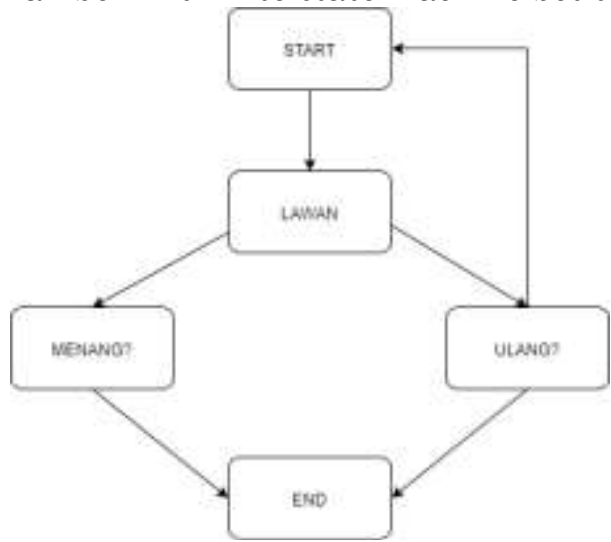

Gambar 4. Finite State Machine Bot jika player memilih menu 1 player

Setelah menjelaskan berdasarkan grafik, beralih ke sistem dalam game, urutan user interface, rule in game, dan lain-lain dijabarkan dalam bentuk flowmap. Flowmap atau bagan alir adalah penggambaran secara grafik langkah-langkah dan urutan prosedur dari suatu program atau prosedur sistem secara logika. Flow map ini berfungsi untuk memodelkan masukan, keluaran, proses 
maupun transaksi dengan menggunakan simbol-simbol tertentu (Megawati, 2016). Peraturan secara rinci dalam permainan digital adalah sebagai berikut :

Peraturan dalam game ini, intinya hanya tidak boleh jari tangan berjumlah 5 , jika berjumlah lebih dari 5, maka jumlah yang lebih dari lima dikurangi 5 , dan itu sisanya. Permainan bisa dilakukan melawan bot atau pun user yang lain, dan peraturan bermain untuk kedua mode ini sama.

\section{Berikut langkah permainannya:}

Tabel 2. Flowmap sistem yang berjalan.

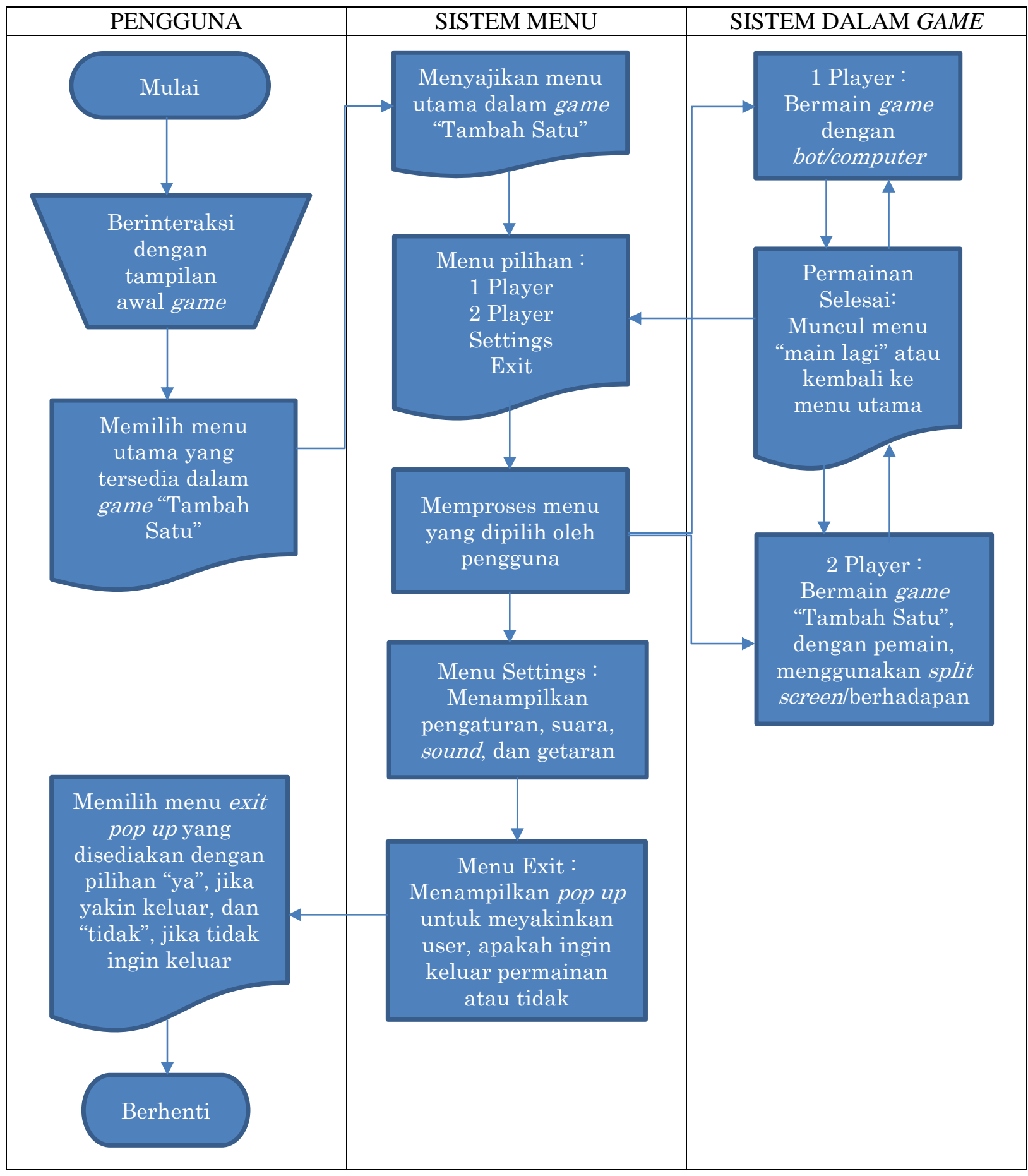

Macam - macam aturan khusus: 
1. Refresh, dimana setiap pemain memiliki kesempatan yang sama dalam menukar jumlah nilai yang dimiliki. Ketika memadupadankan / swap / refresh digunakan, kita kehilangan giliran kita dan lanjut ke giliran lawan.

2. Pemain tidak bisa menggunakan jumlah lebih dari 4 jari tangan

3. Pemain yang menang, berkondisi memiliki sisa jari tangan, dan pemain yang kalah berkondisi dengan jari tangan yang habis terlebih dahulu.

\subsection{Pembangunan game "Tambah Satu"}

Pembangunan game "Tambah Satu" dalam bentuk permainan digital dilakukan dengan pendekatan metode Multimedia Development Life Cycle (MDLC), bertujuan untuk mendapatkan perpaduan aspek kemultimediaan yang tepat guna, dan menarik bagi penggunanya (Nurajizah, 2016). Multimedia Development Life Cycle (MDLC), memiliki 6 tahapan sebagai berikut :

\subsubsection{Concept/Konsep}

Dalam tahap konsep menjelaskan mengenai judul game, pengguna permainan durasi permainan, dan elemen-elemen multimedia yang dibutuhkan, tema, dan karakter yang digunakan. Berikut rinciannya:

Tabel 2. Deskripsi Konsep Game "Tambah Satu".

\begin{tabular}{|l|l|}
\hline Judul & Tambah Satu \\
\hline Pengguna & Umum \\
\hline Durasi permainan & Sampai dinyatakan kalah oleh sistem \\
\hline Teks & Teks untuk petunjuk permainan, dan menu permainan \\
\hline Image & Gambar dan icon (*jpeg) \\
\hline Audio & Instrumen dalam bentuk format Mp3 \\
\hline Animasi & Animasi dalam bentuk 2D \\
\hline Interaktifitas & Tombol dan link \\
\hline Tema & Adu kemampuan strategi dan berhitung \\
\hline Karakter & Terdiri dari 4 karakter tangan (2 pasang) \\
\hline Deskripsi & $\begin{array}{l}\text { Game ini mendeskripsikan permainan "Tambah Satu”, yang dibentuk } \\
\text { kedalam permainan digital agar lebih efisien dimainkan dimana saja dan } \\
\text { kapan saja, dan untuk melesarikan budaya permainan tradisional }\end{array}$ \\
\hline
\end{tabular}

\subsubsection{Design / Desain}

Tabel 3. Perancangan Storyboard Desain

\begin{tabular}{|l||l|l|l|}
\hline \multicolumn{2}{|c|}{ Visual } & \multicolumn{1}{|c|}{ Sketsa } & \multicolumn{1}{c|}{ Audio } \\
\hline $\begin{array}{l}\text { Dalam frame ini, awal menu } \\
\text { game saat game dimulai. } \\
\text { Terdapat judul game, dan tap } \\
\text { dimana saja untuk } \\
\text { melanjutkan. Menu tap } \\
\text { berguna } \\
\text { mempersiapkan pemain. untuk }\end{array}$ & & & $\begin{array}{l}\text { Backsound musik dengan tema riang dan } \\
\text { gembira, dan setiap menyentuh atau klik } \\
\text { akan menimbulkan efek suara. }\end{array}$ \\
$\begin{array}{l}\text { (Storyboard Menu selamat } \\
\text { datang) }\end{array}$ & & \\
& & & \\
& Tapuntuk game & & \\
& & & \\
\hline
\end{tabular}




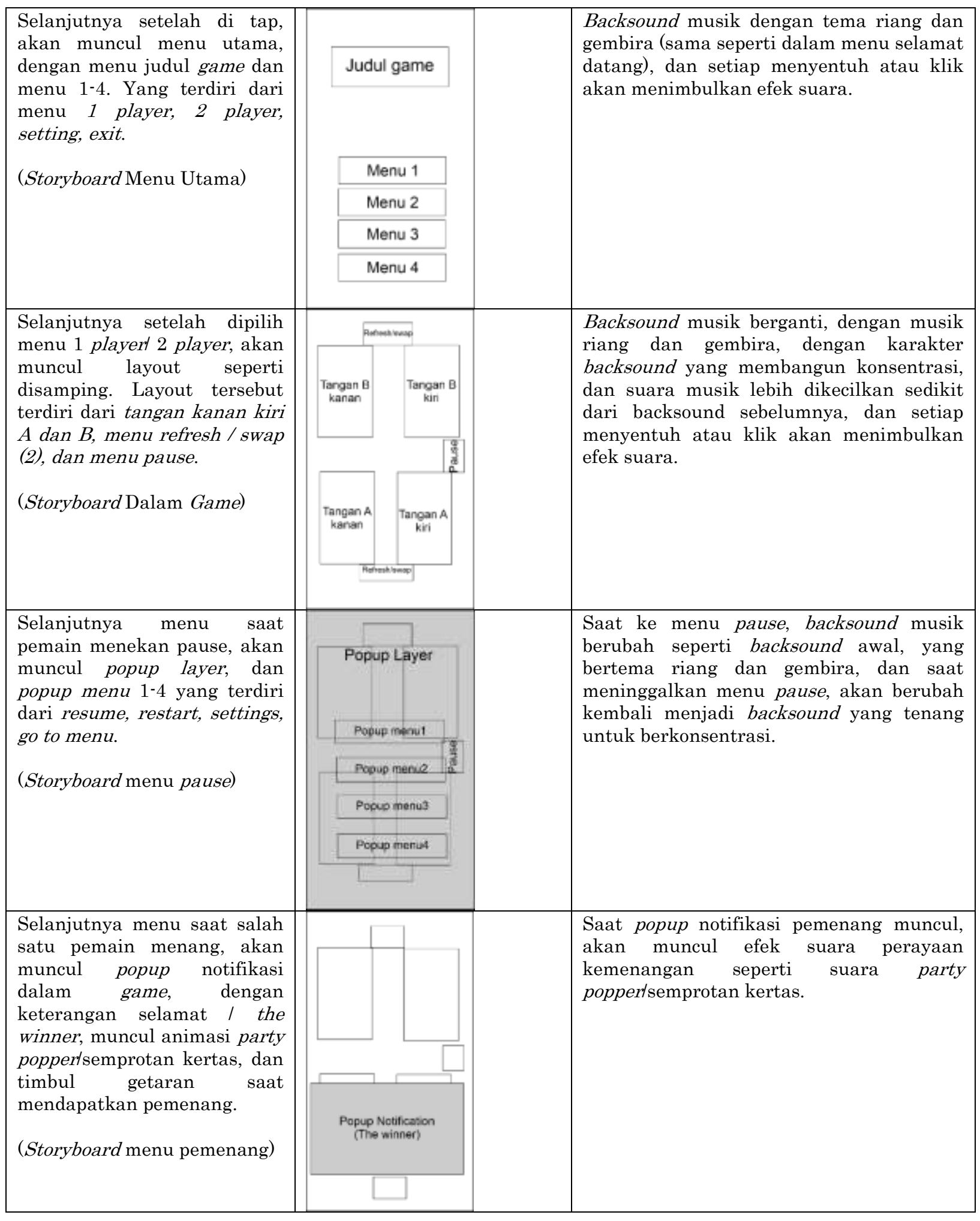




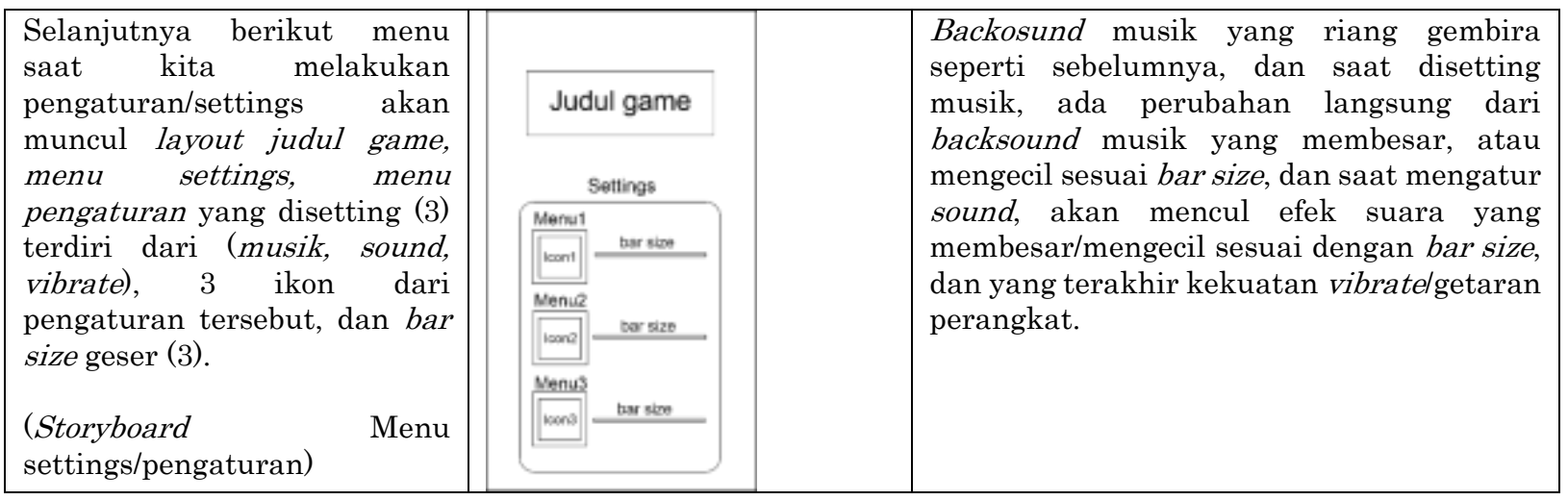

\subsubsection{Obtaining Material Collecting / Pengumpulan Material}

Pengumpulan bahan yang dibutuhkan dapat dilakukan dengan menggunakan aplikasi Corel Draw dalam mendesain setiap panel dalam game tersebut, didesain dalam bentuk vektor, agar gambar dalam panel yang dihasilkan jelas dan tidak pecah-pecah. Dilanjutkan dengan pengumpulan audio, baik suara latar, atau efek suara yang ditimbulkan, menggunakan Youtube Music Library atau suara no-copyright (bebas hak cipta). Lalu lagu dilanjutkan dengan pengeditan suara pada software Audacity.

\subsubsection{Assembly/Penggabungan}

Pada tahap ini melakukan penggabungan semua elemen kemultimediaan dalam game, menggunakan software Game Maker Studio. Dalam penggabungan semua elemen kemultimediaan diperlukan ketelitian yang tinggi, untuk menunjang hasil yang maksimal, terhindar dari banyak error, dan efektif dalam penggunaan waktu

\subsubsection{Testing/Pengujian}

Melakukan Alpha Testing pada game "Tambah Satu", dengan pendekatan Black-Box dengan tujuan untuk menguji fungsionalitas pada sistem dalam game "Tambah Satu", agar game ataupun link pada game dapat berfungsi dengan baik dan terhindar dari kecatatan dalam penggunaan-nya. Pengujian dilakukan hanya sebatas uji game dari sisi developer. Sedangkan pengujian Beta-Testing dilakukan dengan tujuan memvalidasi kegunaan, fungsi, kompabilitas, dan uji reliabilitas dan game "Tambah Satu". Penilaian dilakukan dari dua aspek, penilaian aspek user interface dan penilaian aspek user experience. Penilaian user interface dengan metode heuristic evaluation, dan menggunakan skala guttman, sedangkan penilaian user experience menggunakan metode single ease question, dan menggunakan skala likert.

\subsubsection{Distribution / Penditribusian}

Tahapan ini dapat dilakukan jika semua aspek dalam hal transisi permaianan tradisional ke internasional, dan aspek dalam hal pembangunan game "Tambah Satu" sudah terpenuhi dengan baik dan benar.

\section{Hasil dan Pembahasan}

Game "Tambah Satu" ini dibuat pada device berbasis android. Game dibuat menggunakan Game Maker Studio, bertujuan agar game ini dibuat lebih cepat dan ringan ketika dijalankan di platform Android, iOs, maupun PC. Game ini ditujukan untuk berbagai kalangan dari dewasa hingga anakanak. Tahap desain terdiri dari beberapa tahapan, mulai dari tampilan home atau beranda game, tampilan dalam game, dan tampilan pengaturan. Game ini dirancang agar pengguna bisa bermain sendiri (melawan computer/bot) atau bermain berdua melawan user lainnya, dalam 1 perangkat.

Game"Tambah Satu" ini ditujukan untuk spesifikasi minimal Android Nougat dengan RAM 3.00 GB, berikut penjelasan game secara detail:

\subsection{Tampilan awal game "Tambah Satu"}




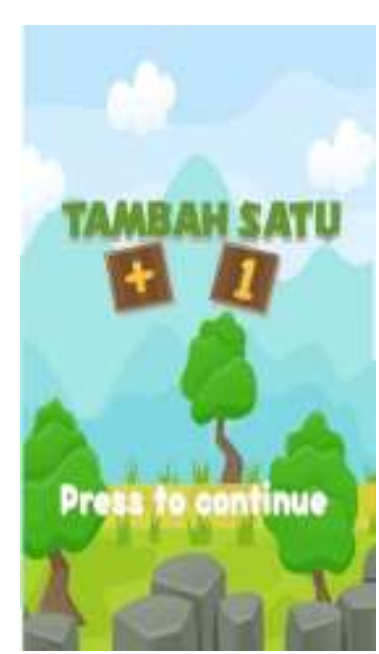

Gambar 5. Tampilan awal ketika memasuki game

Dalam tampilan ini, pemain akan disuguhkan dengan judul dan logo dari game "Tambah Satu", ini, jika pemain sudah siap, sistem menuntut pemain untuk menyentuh layar android dibagian mana pun, untuk memulai game

\subsection{Tampilan Menu dalam game}

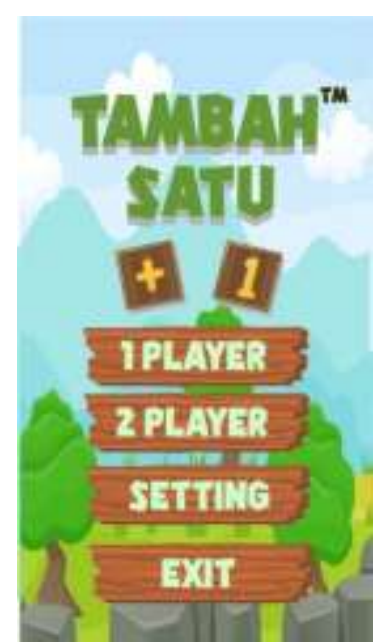

Gambar 6. Tampilan Menu awal saat memasuki game "Tambah Satu"

Pemain akan dihadapkan dengan 4 pilihan menu, yaitu:

\section{Player}

Saat player memilih menu tersebut, pemain akan bermain, dan dihadapkan dengan komputer/bot

2. 2 Player

Saat pemain memilih menu tersebut, pemain akan bermain, dan dihadapkan dengan user lainnya, bersifat offline multiplayer, yang berarti pemain lawan pemain

\section{Setting}

Saat pemain memilih menu tersebut, pemain akan dinavigasikan untuk pengaturan musik, suara, dan getaran perangkat

\section{Exit}

Saat pemain telah menyelesaikan permainan, dan ingin keluar dari Games 


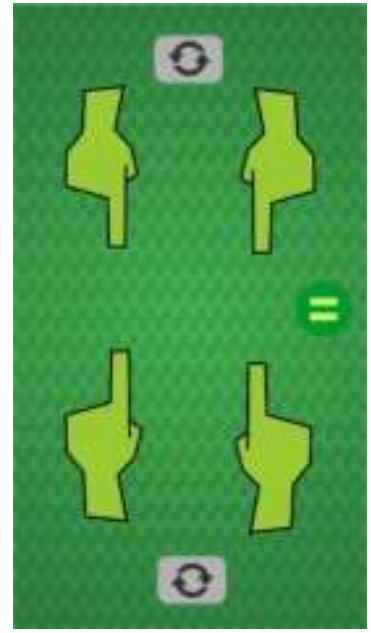

Gambar 7. Saat pemain berada dalam game
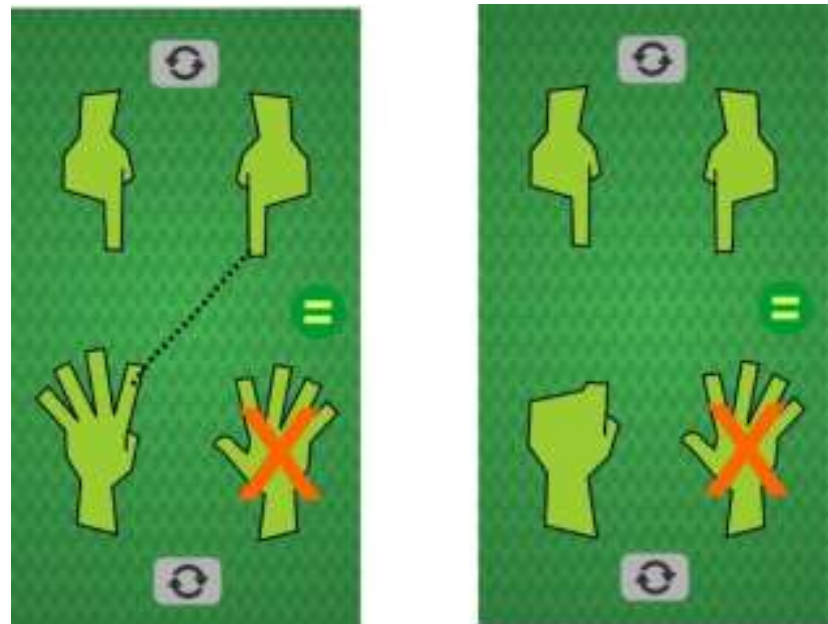

Gambar 8. Tutorialyang diberikan kepada pemain saat berada didalam game

Tutorial yang disuguhkan berupa animasi bergerak antar jari tangan, dan saat pemain baru dalam game, sistem selalu menampilkan tutorial cara bermain, menyerang, memberitahukan keadaan jika menang, dan keadaan jika kalah.

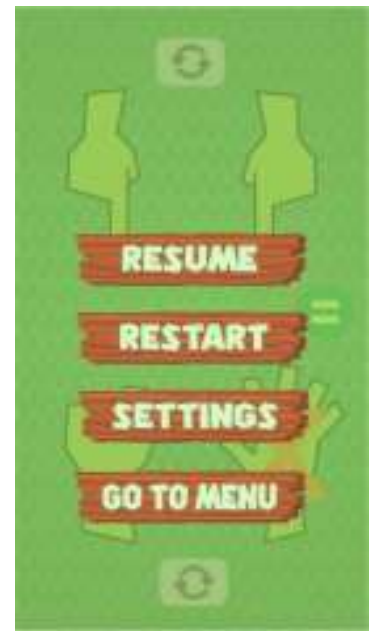

Gambar 9. Menu saat pause game "Tambah Satu".

Saat kita memilih button pause, akan tampil menu popup dengan 4 pilihan menu, resume, restart,settings dan kembali ke menu awal. 


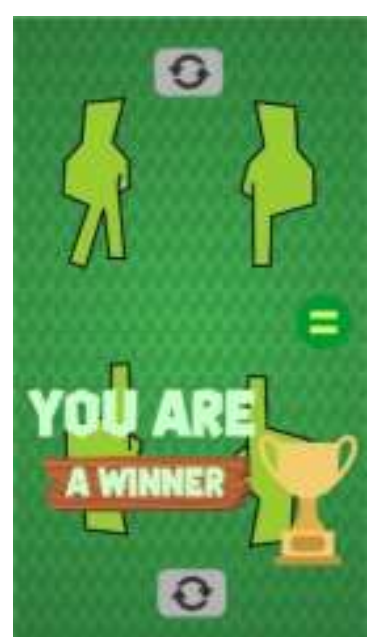

Gambar 10. Tampilan antar muka ketika user memenangkan pertandingan

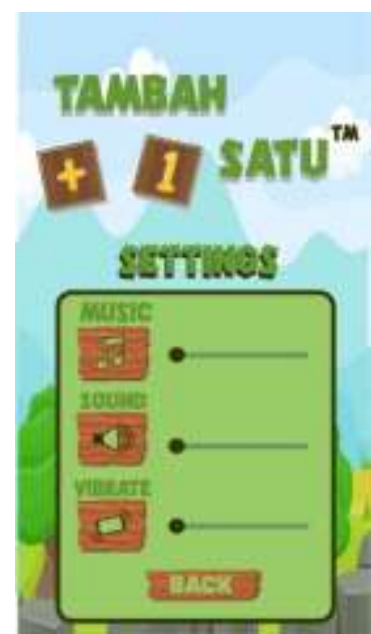

Gambar 11. Tampilan saat pemain memilih menu setting diawal menu

Dalam menu pilihan "settings" pemain akan dihadapi dengan 3 opsi pengaturan, pengaturan musik, pengaturan suara, dan pengaturan getaran besar perangkat.

\subsection{Penilaian kuesioner}

Untuk pengujian game "Tambah Satu", dilakukan dengan menggunakan metode kuesioner dalam aspek penilaian user interface menggunakan metode heuristic evaluation dan user experience menggunakan metode single ease question untuk mengetahui kekurangan dari game tersebut (Supriyono, 2019). Kedua pengujian dilakukan menggunakan kuesioner melibatkan 30 responden, dengan kriteria umur diatas 17 tahun, dan yang secara rutin bermain game digital android.

\subsubsection{Aspek User Interface}

Penilaian dalam aspek user interface game "Tambah Satu" kepada 30 responden menggunakan kuesioner secara terbuka, dengan metode heuristic evaluation dengan penilaian skala guttman dengan kriteria sebagai berikut.

Tabel 4. Interpretasi Nilai Skala Guttman

Dengan aspek yang dinilai sebagai berikut:

\begin{tabular}{|c|c|}
\hline Nilai & Jawaban \\
\hline 0 & Tidak \\
\hline $0,10-0,33$ & Mendekati tidak \\
\hline $0,34-0,66$ & Netral \\
\hline $0,67-0,99$ & Mendekati ya \\
\hline 1 & Ya \\
\hline
\end{tabular}


1. H1 - Visibility of system Status (Feedback)

2. H2 - Match between system and the real world (Metaphor)

3. $\mathrm{H} 3$ - Use control and freedom (Navigation)

4. H4 - Consistency and standard (Consistency)

5. H5 - Error prevention (Prevention)

6. H6 - Recognition rather than recall (Memory)

7. H7 - Flexibility and efficient of use (Efficiency)

8. $\mathrm{H} 8$ - Aesthetic and minimalist desain (Design)

9. H9 - Help users recognize, dialogue, and recoverys from errors (recovery)

10. H10 - Help and documentation (Help)

Dan berikut hasil dari kuesioner tersebut:

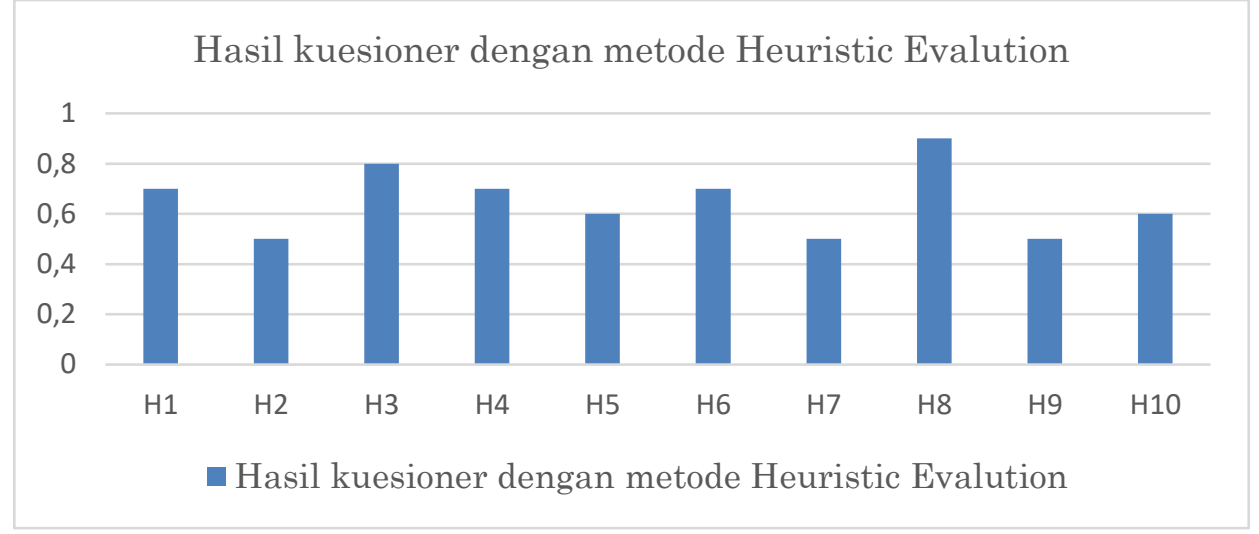

Tabel 5. Tabel Hasil metode Heuristic Evaluation

\begin{tabular}{|c|c|}
\hline \multicolumn{1}{|l|}{ Fungsi } & Nilai \\
\hline $\mathrm{H} 1$ & 0.7 \\
\hline $\mathrm{H} 2$ & 0.5 \\
\hline $\mathrm{H} 3$ & 0.8 \\
\hline $\mathrm{H} 4$ & 0.7 \\
\hline $\mathrm{H} 5$ & 0.6 \\
\hline $\mathrm{H} 6$ & 0.7 \\
\hline $\mathrm{H} 7$ & 0.5 \\
\hline $\mathrm{H} 8$ & 0.9 \\
\hline $\mathrm{H} 9$ & 0.5 \\
\hline H10 & 0.6 \\
\hline Rata-rata & $\underline{0.65}$ \\
\hline
\end{tabular}

\subsubsection{Aspek User Experience}

User experience merupakan penilaian terhadap apa yang pengguna rasakan saat menggunakan game tersebut, penilaian user experience meliputi perangkat lunak, konten, dan hiburan yang disuguhkan (Supriyono, 2019). Dalam penilaian ketiga aspek tersebut menggunakan kuesioner single ease question dengan skala penilaian menggunakan skala likert, dengan kriteria skala sebagai berikut:

Tabel 6. Skala pengukuran Likert

Dengan aspek yang dinilai sebagai berikut:

\begin{tabular}{|c|c|}
\hline Nilai & Skala \\
\hline 1 & Sangat sulit \\
\hline $2-2,9$ & Sulit \\
\hline $3-3,9$ & Cukup sulit \\
\hline $4-4,9$ & Cukup mudah \\
\hline $5-5,9$ & Cukup mudah \\
\hline $6-6,9$ & Mudah \\
\hline $7-7,9$ & Sangat mudah \\
\hline
\end{tabular}




\section{Fungsi menu F1- 1 Player}

Tugas yang diberikan kepada responden yaitu membuka aplikasi game, dan menekan layar intro, lalu menekan tombol 1 player.

2. Fungsi menu F2- 2 Player

Tugas yang diberikan kepada responden yaitu membuka aplikasi game, dan menekan layar intro, lalu memilih tombol 2 player.

3. Fungsi menu F3- Settings

Tugas yang diberikan adalah mencari tombol settings dalam game, menemukan tombol tersebut, dan mengkonfigurasi tombol settings tersebut

4. Fungsi menu F4- Exit

Tugas yang diberikan kepasa responden yaitu membuka aplikasi game "Tambah Satu", lalu menekan layar intro, dan diakhiri dengan menekan tombol exit.

Dan berikut hasil dari kuesioner tersebut:

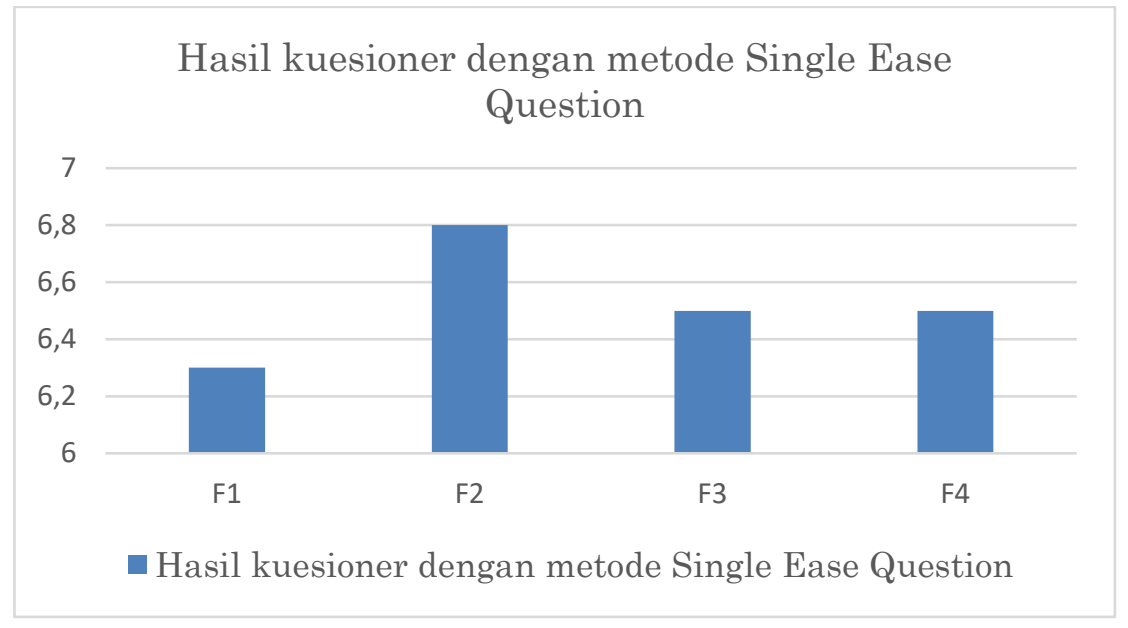

Tabel 7. Hasil metode Single Ease Question

\begin{tabular}{|c|l|}
\hline Fungsi & \multicolumn{1}{|c|}{ Nilai } \\
\hline F1 & 6.3 \\
\hline F2 & 6.8 \\
\hline F3 & 6.2 \\
\hline F4 & 6.5 \\
\hline Rata-rata & 6.45 \\
\hline
\end{tabular}

\section{Simpulan}

Game "Tambah Satu", merupakan game berbasis android, bergenre role playing games, dan bersifat offline multiplayer, ditujukan untuk melestarikan atau pengembangan permainan tradisional yang dimodernisasi, dan menyesuaikan dengan perkembangan jaman. Dari segi user interface, game "Tambah Satu" menghasilkan rata-rata sebesar 0,65 dikategorikan sebagai netral digunakan oleh pengguna, dan penilaian dari segi user experience didapatkan sebesar 6,45, diketegorikan mudah, digunakan oleh pengguna.

Ada beberapa saran dari pengguna untuk developer untuk game "Tambah Satu", yaitu:

1. Menambah animasi bergerak sebagai daya tarik, dikarenakan game "Tambah Satu", ditujukan bukan hanya untuk orang dewasa, melainkan juga anak-anak, dan akan didominasi oleh kalangan anak-anak.

2. Dikarenakan kebanyakan game berbasis android bergenre online, akan lebih baik jika game "Tambah Satu", mengikuti perkembangan game masa kini. 


\section{Ucapan Terima Kasih}

Saya mengucapkan terima kasih kepada Tuhan Yang Maha Esa, atas berkat rahmatnya jurnal berjudul "Rancang Bangun Game Tradisional "Tambah Satu" berbasis platform Android', dapat terselesaikan semaksimal mungkin. Terlebih banyak pihak yang terlibat dalam terciptanya jurnal, terima kasih kepada dosen saya bu Ayung Candra, terima kasih atas bimbingannya selama pembuatan jurnal tersebut. Dan terutama kepada orang tua saya yang telah mendukung saya dalam pembuatan jurnal ini. Terima kasih semuanya.

\section{Daftar Pustaka}

1. Hikmah, N. (2017, Oktober 06). Kompas Gramedia. Retrieved from kompasiana: https://www.kompasiana.com/nur_hik/59d6570c7ac66513b7641162/memudarnya-minatanak-anak-terhadap-permainan-tradisional.

2. Sari, M. P., Rinjani, D., \& Hidayah, N. Rancang Bangun Video Cerita Rakyat Nusantara "Lok Sinaga". Edsence: Jurnal Pendidikan Multimedia, 1(2), 79-88.

3. Suyasa, I. M. A., Buana, P. W., \& Purnawan, I. K. A. (2017). Perancangan Aplikasi Game Warung Sate Lilit Bali Berbasis Android Sebagai Media Pembelajaran Pengenalan Sate Lilit Secara Sederhana. Jurnal Ilmiah Merpati (Menara Penelitian Akademika Teknologi Informasi), 42-51.

4. Permana, F. C., Padmasari, A. C., \& Sylviani, S. (2019). Rancang Bangun Aplikasi Pendeteksi Jenis Golongan Darah Berdasarkan Konsep Kepercayaan Rakyat Jepang (Minkan Shinkō). Edsence: Jurnal Pendidikan Multimedia, 1(1), 25-34.

5. Padmasari, A. C., Nurindiyani, A. K., \& Anggraeni, I. (2019). Penerapan Model Decision Tree untuk Rancangan Game Multiplayer Berbasis Jaringan (Uka-Uka Tresure Hunter). Edsence: Jurnal Pendidikan Multimedia, 1(1), 19-24.

6. Krisnawan, I. B. D. (2016). Rancang Bangun Game Edukasi "Lawar Bali" pada Platform Android. Jurnal Ilmiah Merpati (Menara Penelitian Akademika Teknologi Informasi).

7. Alam, S. T., Nugroho, R. A., \& Budiman, I. (2017). Rancang Bangun Aplikasi Permainan (Games) Sebagai Media Pembelajaran Seni dan Budaya Banjar. Klik-Kumpulan Jurnal Ilmu Komputer, 1(1), 90-102.

8. Sanjaya, C. B. M. (2016). Rancang Bangun Aplikasi Game Edukasi Bahasa Bali pada Platform Android. Jurnal Ilmiah Merpati (Menara Penelitian Akademika Teknologi Informasi).

9. Hidayat, E. W., Aldya, A. P., \& Miranti, P. T. A. (2019). Game Adu Muncang Berbasis Android. Innovation in Research of Informatics (INNOVATICS), 1(1).

10. Megawati, M. (2016). Rancang Bangun Aplikasi Pengenalan dan Simulasi Permainan Tradisional Nusantara Berbasis Android (Doctoral dissertation, Universitas Islam Negeri Alauddin Makassar).

11. Nurajizah, S. (2016). Implementasi Multimedia Development Life Cycle Pada Aplikasi Pengenalan Lagu Anak-Anak Berbasis Multimedia. PROSISKO: Jurnal Pengembangan Riset dan Observasi Sistem Komputer, 3(2).

12. Supriyono, N. D., Aziz, A., \& Harianto, W. (2019). Analisis User Interface Dan User Experience Pada Game Perang Komando Menggunakan Metode Heuristic Evaluation. Semnas SENASTEK Unikama 2019, 2. 